\title{
Direct cash transfer to resolve the crisis of income inequality
}

\begin{abstract}
Income refers to the monetary returns that a person gets in the form of wages, salaries, interest on savings etc. for some investment of work or for selling a product or rendering a service. Having a sizable sustainable income to take care of your daily needs and protecting your interests in the years to come is the most basic aspiration of every citizen in this world. Income Inequality is one of the worst social security problems the world is facing at this moment. According to the survey released by Forbes in 2017, the top three richest individuals in terms of net wealth in the United States, namely Bill Gates, Jeff Bezos, and Warren Buffett, now own more wealth than the entire bottom 50 percent of the American population combined, which is approximately 160 million people or 63 million households. The scenario in India is ever worse. According to the recently released study by Oxfam in 2017 , the top $1 \%$ in India owns $73 \%$ of wealth. The same scenario was $1 \%$ of the richest earning 53\% wealth in 2015 according to Credit Suisse. The popularity of the Occupy Wall Street Movement testifies to the fact the issue of income inequality finds support across borders, ideologies, political affiliations and internal socio political scenarios.
\end{abstract}

If we don't reverse this trend now, wealth will keep accumulating in the hands of the fewer and fewer individuals, a trend which we have been witnessing through the decades. Without the basic availability of minimum credit, the income gap is bound to widen and wealth concentration is going to increase.

Measures like the Microcredit revolution started by Grameen Bank under Mohammad Yunus and the direct cash transfer schemes are some attempts to relieve the world of the most important social security problem in front of mankind: Income Inequality. Governments around the world have tried to resolve the issue of low income people with ventures like income redistribution, subsidies, reservation etc. but have been skeptical about the Direct Cash Transfers (DCT). The advantage of the Direct Cash Transfers is that the rich will continue having a great share of the world's wealth but will help lift several poor individuals from poverty. The paper discussed the viability of the direct cash transfer mechanism to effectively tackle the issue of income inequality.

Keywords: income inequality, poverty, cash transfers, public policy
Volume 2 Issue $3-2018$

\author{
Kshitij Naikade \\ Symbiosis International University, India
}

Correspondence: Kshitij Naikade, Symbiosis International University, India, Tel 09619292797,

Email kshitijnaikade@gmail.com, kshitij.naikade@symlaw.ac.in

Received: April 20, 2018 | Published: May 02, 2018

\section{Objectives}

a. To study the magnitude of the problem of Income Equality.

b. To study the existing mechanisms and measures and the reasons for their failures to stop income inequality.

c. To analyze the existing counter-effects of wealth concentration and predicting the impending consequences.

d. To suggest Direct Cash Transfer (DCT) as a viable solution to reverse the trends of Income Inequality and in turn eradicate rampant poverty.

\section{Material and methods}

The researcher has done a doctrinal and applied research which is based on qualitative analysis. The researcher has used exploratory \& analytical research design for the current study critically looking at various estimates and giving viable plausible alternatives based on data analysis and theoretical understanding of the problem at hand. The researcher has used secondary sources for data collection like books, journals, online data bases, research publications, articles, authentic surveys conducted by prominent nonprofit agencies, government reports, poverty estimation charts, census data etc.

\section{Scope of Study}

The study seeks to address the magnitude of the problem of income inequality in the evolution of modern societies from a pre industrial era to a globalised developed state. It seeks to address the loopholes in the existing mechanisms to tackle the long standing problem of poverty, wealth concentration and income inequality. Movements like the occupy wall street movement, which are getting asserted around the globe by several interest groups is studied objectively and their demands and expectations are taken into consideration.. The researcher is looking at the problem in a holistic way to bring about collective socio economic change to address the issues of the subaltern group which do not find any voice in the socio, political discourse of the land. Direct Cash Transfers (DCT) have been looked at as an alternative to the existing redistribution mechanisms in developing countries. The researcher is looking at DCT to extend its scope and relive the world of the stigma of income inequality.

\section{Income inequality as a social menace: an introduction}

The problem of wealth concentration directly threatens human existence in the long run. If wealth is concentrated in the hands of 
few, the development of civilization in totality is threatened. Also, as wealth concentration increases, pushing the world to fight for even basic resources, the fight for survival is already real and at our doorstep. In the near future it can even prompt armed conflicts in several countries leading to disastrous and bloody consequences. The water wars that we see in developing and underdeveloped countries are a testimony to the fact that if we don't share and sustainably use our resources, it's going to be a threat to the survival of human kind.

According to a report by Oxfam ${ }^{1}$ in 2010, the world's richest 388 people had more amount of wealth than the entire bottom 50 percent of the world population, a group which has more than 3.3 billion people. In January 2017, Oxfam conducted a similar survey which showed that the number of ultra rich people have come down from 388 to 8 who own more wealth than half of mankind. These 8 people might not be necessarily bad individuals who have achieved wealth by illegal and immoral means or are evil manipulators who have reached where they are by bribing and rigging the system. They might be conscientious, honest people who have become rich by hard work and smart business strategies. However, these 8 individuals will definitely, impose their will on the world by the sheer pull of economic power that they have. In such a scenario, income equality can prove to be fatal and detrimental to human development. It can easily happen in a country like Bangladesh where multinational corporations from Germany have become so influential that they definitely influence the domestic policy making in Bangladesh, thus, raising question marks over the sovereignty of Independent nations. The wealth of these Multi National Corporations (MNCs) owned by these super rich are more than the Gross Domestic Product (GDP) of several countries put together. ${ }^{2}$ And it is not to say that only the developing or underdeveloped nations will be impacted by this, even developed countries can too be held to ransom by these super rich individuals/ Trans National Corporations (TNC').

In the recently concluded election campaign in the United States in 2016, the Democratic Party senator, Bernie Sanders, too was hinting at the fact that $0.1 \%$ Americans own as much wealth as the bottom 90 . His claims were supported by solid data given by the National Bureau of Economic Research, making Bernie Sanders' statements sound like a death knell on the poor in a rich developed country like USA. ${ }^{3}$ The Occupy Wall Street Movement which got a lot of support around the world also focused on how the concentration of wealth around the world has stunted the development discourse. The Walton Family, who are the owners of the Walmart group own more wealth than 40 $\%$ of US Population, a fact supported by another unbiased research. Thus, here, Direct Cash Transfers can prove to be a boon in disguise.

In India, the scenario is not different, where $73 \%$ of the wealth generated in 2017 went to the richest $1 \%$ of the population of the country; while at the same time about 67 crore Indians who constitute the poorest $50 \%$ of the population saw only $1 \%$ increase in their wealth in the same time period. ${ }^{4}$

1"Just 8 Men Own Same Wealth as Half the World. (2017, January 16) Retrieved March 1, 2018, from Oxfam International.

${ }^{2}$ Green D. (2016, September 20). The world's top 100 economies: 31 countries; 69 corporations-World Bank . Retrieved March 1, 2018, from World Bank

${ }^{3}$ Zucman ES. (2014, October). Wealth Inequality in the United States since

1913 : Evidence from Capitalized Income Tax Data. Cambridge: National Bureau of Economic Research.

${ }^{4}$ Pimente DA. (2018, January). Reward Work, Not Wealth-To end the Inequality Crisis. Oxford: Oxfam International
In the last 12 months in 2017 the wealth of this elite group of $1 \%$ people increased by Rs 20,913 billion. This amount is equivalent to total budget of Central Government of India in 2017-18. ${ }^{5}$ According to the same survey, it takes just 4 days for a Chief Executive Officer from one of the top five global fashion brands to earn what a Bangladeshi garment worker will earn in her entire lifetime. In the US, it takes slightly over one working day for a CEO to earn what an ordinary worker in Bangladesh makes in a year.

Compare this with another report by the Johannesburg-based company New World Wealth, which came out in 2016, India is the second-most unequal country globally, with millionaires controlling more than half of its wealth with a total individual wealth of $\$ 5,600$ billion, it's among the 10 richest countries in the world - and yet the average Indian is relatively poor. ${ }^{6}$

Whereas poverty involves absolute deprivation in terms of lack of income, wealth and basic access to public resources, income inequality is more relative where ones income is less compared to someone else and has therefore been ignored over the years in our quest for industrial globalised societies. It is a problem which everyone knows and identifies with easily as it's so apparent, but more often than not the effort has not gone beyond lip service. In a country like India, the leaders who seek power are usually seen or heard talking and sympathizing with the poor and are visibly pained by the vulgar income inequality in India. However when the same leaders are elected and hold positions of power they are usually seen filling their cabinets with millionaires or people with unreal amounts of wealth accumulated through several business interests. Recently the disclosure of Manik Sarkar, the former Chief Minister of Tripura that his bank account has only 2410 rupees and owns no assets was met with shock and awe. ${ }^{7}$ We have simply got accustomed to the senseless mind numbing display of concentrated accumulated wealth by our politicians.

Thomas Piketty, in his book, Capital in the 21st Century, admits to modern capitalism promoting income inequality and suggests progressive taxation to remedy the problems created by the concentration of wealth. However, going one step ahead we can definitely include DCT in its ambit and strategically redistribute this progressively collected tax so that the public policy covers maximum people. The administrative machinery in a country like India is admittedly inadequate to resolve basic civic issues of people. Thus, time has come to put some of the onus on people to take care of their own well being. But for that we need to empower them and train them to fight for their sustainable survival. For that end, DCT can help us reach a much wider audience. The Invisible hand of the market which we relied upon to resolve our issues has strangely been helping only the rich and influential and thus has to be objectively evaluated and changed to make it more egalitarian. DCT is the solution which seeks to address this gaping anomaly of economics. By providing direct cash transfers, we are not threatening the wealthy minority, but uplifting the poor majority, who will in turn enjoy a better standard of living, which in turn will help in the socio political economic environment of the nation, which will then as a result be beneficial for everyone,

${ }^{5}$ (Finance, 2018-19) Finance, MO. (2018-19, March 11). Budget at a Glance. Retrieved March 24, 2017, from Union Budget- Ministry of Finance

${ }^{6}(2016)$. India Human Development Survey . Johannesberg : New World Health.

${ }^{7}$ Tripura CM-India's Poorest CM's. (2018, February 1). Retrieved March 20, 2018. 
including the wealth minority. Thus, the DCT is a win-win scenario for everyone in the society.

The issue of income inequality is even more shocking in Democracies where these very basic human rights of people are expected to be protected by constitution or by the law of the land. However as the US Supreme court judge, Louis Brandies very infamously opined recently "We can have democracy in this country or have great wealth concentrated in the hands of the few, but we cannot have both". ${ }^{8}$ We need to get out of this pessimism and look for better implementable alternatives.

\section{Direct cash transfers}

Cash transfers can be defined as instruments through which recipients are empowered with purchasing power by giving them money, to acquire specific goods of their choice rather than giving them subsidized goods themselves. In a welfare state economy, in kind subsidies are usually given, where sale or distribution is done by the government, at less than market price.

There are two types of cash transfers, conditional and unconditional Conditional ones are where the government gives you cash only when you fulfill some basic government duties or pre conditions. These transfers can be for a specific type of households, contingents or occupation group. India's flagship National Rural Employment Guarantee Scheme, the world's largest employment guarantee program and which requires mammoth proportions of administrative coordination, is nothing but a conditional cash transfer program. Unconditional cash transfers are the ones where the government provides with resources with no strings attached and the beneficiary is free to use his money the way he wants to and decide upon his priorities in terms of spending. These unconditional cash transfers can be universal or specific to a particular age group or underdeveloped depressed section of the population. Some unconditional social security programmes ${ }^{9}$ launched by the government, whose intention is to change the behavior of the society towards girl children are also examples of the same. There is also a third category called "cash assisted kind" transfers which is sometimes used in several social security programs. In this category, money is given to the beneficiary but only for a specific pre defined purpose. Example: Government of Tamil Nadu gave free bicycles to girls who complete a particular grade in school. This is an example of an in-kind transfer. On the other hand, the Bihar government started a program through which they gave cash to families to buy the bicycle only. This is an example of "cash-assisted kind" transfer.

It is import for us to understand that the cash transfers the researcher is proposing will have to be implemented as a substitute to the existing social security mechanisms which have completely failed to achieve its objectives in the last 70 years. However, for Direct Cash Transfers (DCTs) to be successful it has to be complemented by government intervention in creating basic infrastructure and providing favorable ground for trade and industry to function. Otherwise the receiver will use the cash transfer meant to fulfill his tertiary needs to fulfill his primary needs, thus defeating the very basic purpose of giving cash transfers to reduce income inequality. DCT can also help us create some achievable end goals through which the policy

${ }^{8}$ Louis D. Brand; Legacy Fund for Social Justice

${ }^{9}$ Dutta PS. (2010) "Small But Effective: India's Targeted Unconditional Cash Trans fers". Economic and Political Weekly, 40-45. intervention can have a plausible exit clause, which is seldom found in any policy intervention to reduce poverty or income inequality. Also, more importantly, the $73 \mathrm{rd}$ and $74 \mathrm{~h}$ Amendment were introduced because the government realized that in a huge country like India with its varied needs and demands, it's difficult for the administration to cater to its expectations. That is the reason why the Panchayati Raj Institutions were empowered to deal with local issues. The DCT Is also an extension of that effort to let people decide for themselves what is best for them rather than be dependent on a centrally taken decision or directive, which might not be in sync with the grassroots reality.

\section{Direct cash transfers: realistic solution}

The AADHAR or the UIDIA program can be debated for its validity in India and the right to privacy can be a separate discussion, but the fact that is that the AADHAR program can be integrated in the DCT mechanism along with the government's flagship JAM Trinity to streamline the recipients and plug the loopholes of the existing system. One such example was the introduction of biometric registration in Andhra Pradesh which showed that almost $12 \%$ of social transfer recipients were non-existent. This was more glaring and shameful because it was supposedly in a state where this programme was considered as one of the best run in India. ${ }^{10}$ By providing direct cash transfer it was proved that the purchasing power of Individuals has increased considerable and the benefactors are in a position to buy those goods and services which the government should have provided in the first place long time ago, but which it has failed to do so. A case in point would be the kerosene subsidies that we incur every year as we believe that rural $\&$ urban ration card holders use it for cooking purposes. However, in both rural and urban areas, the use of kerosene is minimal for cooking. Statistics show that the proportion of rural households in the whole of India whose primary source of energy for cooking was primarily kerosene came down from $2.0 \%$ in 2001-02 to $0.6 \%$ in 2007-08 while in the same time period, for the urban households it fell from $15.3 \%$ to $7.6 \%{ }^{11}$

However, because of the cheap availability of kerosene, its use has been rampant in the adultery of petrol and diesel, thus having serious distortions. The fact that India has the lowest prices of kerosene in South Asia after the subsidies have been taken into consideration has led to its misuse through the public distribution programme, thus creating a black market and an entire mafia which deals with adulterated petrol and oil.

A survey by the National Council of Applied Economic Research showed that the total leakage/diversion of kerosene meant for distribution under the Public Distribution System (PDS) to be as high as $38.6 \% .^{12}$ This is not only detrimental to the interests of the poor in this country but it also offsets the efforts of the government as the intentions of the government have not been addressed and has not reached the people for whom it was intended and also erodes public finances which could have been better utilized in another important

${ }^{10}$ Johnson D. (2008): "Case Study on the Use of Smart cards to Deliver Government Benefits in Andhra Pradesh, India", Institute for Financial Management and Research.

${ }^{11}$ National Sample Survey Organization (2010): "Household Consumer Expenditure in India, 2007-08: NSS 64th Round" Report No. 530, Ministry of Statistics and Programme Implementation, Government of India.

${ }^{12}$ NCAER Estimates $38.6 \%$ of PDS Kerosene Leaked/Diverted by Unscrupulous Elements (2011), March 10. 
scheme or policy program. Simple mathematics will tell you that with kerosene subsidies exceeding Rs 20,000 crore, a nearly $40 \%$ rate of illegal diversion implies criminal wastage of expenditure of Rs 8,000 crore. It also increases pollution from the adulterated petrol and crimes related to fuel related conflicts are on the rise and have a major socio political repercussion, which has made it a political touch me not issue. If the same scheme is rechannelized through a direct cash transfer mechanism and prices of kerosene are increased keeping into consideration market demands and compulsions, it would reduce pollution, criminal tendencies and more importantly help in effective utilization of government resources to achieve policy ends. Clientalism, Patronage and corruption which have been the hallmark of the existing social security policies to eliminate income inequality and poverty will be arrested if DCT as an effective mechanism s introduced.

Also cash transfers are cost effective as they reduce all the middlemen \& transaction costs. The costs of shipping, transporting, distribution are also avoided as the onus is on the beneficiary to go to the market and buy the commodities and not on to government to provide it to him at his doorstep. In a huge country like India, where decentralization is looked at as only solution to solve the huge administrative tangle, DCT can be an effective mechanism to resolve the issues coming out of the existing PDS. Also, DCT allows the beneficiary the flexibility to direct his expenses as per his domestic demands and not in a general sense which the government expects when it gives subsidized goods and commodities or through CCT. Skeptics however feel that in a patriarchal society of India where the expenses are even today majorly controlled by the male member of the family, effective utilization would be hampered and rational educated decision making in terms of spending might not take place. However, there are studies which suggest that when this same cash has been specifically targeted at women or when directly given to women of the household ${ }^{13}$ it has given them greater intra-household control ${ }^{14}$ By giving people the freedom to spend their money as per their wishes, we are expanding the choices and eliminating the paternalistic approach which has been the government's bane since Independence.

The most important consequence of income inequality is that it doesn't leave enough money with the people to cater to unforeseen circumstances or matters of emergency and are therefore trapped more often than not in a debt trap, a scenario on which the moneylender economy thrives. Reports from Namibia and South Africa ${ }^{15}$ have proved that DCT to the elderly and for beneficiaries of the health policy have pulled them out of poverty, helped them prevent falling prey to epidemics and invest in a better standard of living for themselves and their family. A similar survey in India too showed positive results, thus proving the efficacy of the unconditional DCT helping reduce income inequality in the long run and pulling people out of poverty. ${ }^{16}$

\footnotetext{
${ }^{13}$ Adato BD. (2003) "The Impact of Progresa on Women's Status and Intrahousehold Relations" in A R Quisumbing (ed.), . Household Decisions, Gender and Development: Synthesis of recent Research , 50-60.

${ }^{14}$ Attanasio OA. (2002) "Test of Income Pooling in Household Decisions". Review of Economic Dynamics , 5 (4), pp 720-48.

${ }^{15}$ Sam son MU. (2004) Final Report: The Social and Economic Impact of South Africa's Social Security System South Africa. Economic Policy Research, 272279

${ }^{16}$ Dutta Puja. Stephen Howes and Rinku Murgai (2010): "Small but Effective: India's Targeted Unconditional Cash Transfers", Economic \& Political Weekly, 45(52), p 63.
}

Starting new policies with the aim of giving DCT or modifying the existing arrangements to accommodate DCT can be some kind of a starting point for government action henceforth. Indira Aawas Yojana (IAY) is something that can be argued to be included in this bracket, where money should be given to the needy, but whether to build a house with that money or invest it in his livelihood or business activity should be his prerogative. The Public Distribution System (PDS) in India, which is arguably one of the world's largest, has faced several drawbacks in terms of corruption scandals, Food Corporation of India (FCI) controversies where grain is rotting instead of reaching the hungry stomachs, middlemen nexus turning into a politically influential lobby etc. It's time the government instead making minor temporary firefighting changes, overhauls the entire distribution system and engages in DCT and reduce the logistics and distribution costs and use that money in turn to increase funding for the DCT, thus helping in reducing Income Inequality. Increased government intervention to control the markets or curtail inflation has not proved to be beneficial till date. It's time the government changes its strategy and gives more money to the people through DCT. This increased spending and purchasing capacity will in turn regulate the market on its own and the invisible hand of the market will indeed remain invisible. This will go a long way in bringing down the rampant inequality in the society.

\section{Cash transfers: magic pill?}

"Tactics without strategy is the noise before defeat." ${ }^{17}$ Direct Cash Transfer mechanism is a debatable but nevertheless effective method to tide over some of the inefficiencies in the various subsidy based schemes, programs carried out by our "Welfare State" to help in overcoming income inequality. The very basic juvenile understanding is that efforts like Direct Cash Transfer make the receiver a passive participant of the political process where they do nothing to strengthen the political skills, actions and awareness of the receiver. However if we connect the dots using the efforts like MNREGA as a case study which are the government's effort at providing assured work as part of its welfare responsibilities making the recipient an active participant, it will, thus go a long way in helping reduce poverty and income inequality. However, because of this pessimistic view cash transfers have been looked at suspiciously in India by analysts, activists and political commentators, where conventional socialistic methods of delivering goods, services, and infrastructure have been comfortably assimilated in the system.

However, cash transfers, if implemented in a systematic way with good solid groundwork can definitely help in easing out some of the concerns. Cash transfers, in a country like India where implementation can be a logistical nightmare even for the most well laid out plans due to its huge size and population can be a boon in disguise. Conditional cash transfers, in a way in which people actively participate in the program with a well managed incentive structure, have shown positive results across the world where they have been tried on experimental basis, more so in several African nations, and have also been recognized as a cost effective medium to deliver the objectives. Cash transfers help reduce the role of the middleman and the intermediary which is the biggest recognized problem of leakages and corruption in the welfare distribution mechanism, especially the Public distribution System (PDS) in India. If the Rs. $1,80,000$ crore spent on CSS (centrally sponsored schemes) like

\footnotetext{
${ }^{17}$ Tsu S. (2017) The Art of War (Illustrated). Moskva: Aegitas.
} 
food, fertilizer and fuel subsidies were distributed equally to the 70 million poor households, it would mean a monthly transfer of over Rs. 2,140/ household, which will be enough for them to come out of poverty. ${ }^{18}$ Although too simplistic in its explanation, it just put into perspective the amount of money we spend every year compared to the disappointing results we have in front of us in the last 7 decades. Rajiv Gandhi, the former PM of India had said, rather (in) famously, that of every 1 rupee spend by the government, only 15 paisa reaches the intended beneficiary, a fact although sounding exaggerated was corroborated by the deputy chairman of the planning commission, Dr. Montek Singh Ahluwalia, in 2009, thus proving that conventional methods have proved ineffective in dealing with the huge effective demand. In such a scenario, the direct cash transfer offers quick and seamless transfer of funds directly to the accounts of the beneficiaries. Recently, in several cases across India, where crops were damaged due to natural calamities like hailstorms, the compensation money was transferred to the bank accounts without delay. The financial inclusion drive started aggressively by the government under the JAM trinity (Jan Dhan, Aadhar, Mobile) has helped crores of Indian's open bank accounts, get registered under UIDAI (Aadhar-Unique Identification Authority of India), helping create a database. The states of Karnataka and Kerala have used elements of the JAM trinity effectively to reach intended beneficiaries in the Public Distribution Scheme (PDS) scheme and to monitor delivery of food grains more effectively. ${ }^{19}$

There is a criticism that by initiating DCT the government is trying to shrink away from its responsibilities. However, as mentioned in the above arguments, cash transfers need not be used as a substitute to the current subsidy based programs initially but can be used complimentarily to plug the loopholes and strengthen the delivery mechanism till it can stand on its feet and be used as a standalone public policy. Just like there are targeted and universal social security programs, we can have targeted cash transfer for some parts of a policy where leakages are widespread. ${ }^{20}$ Calculations from the National Sample Survey (NSS) suggest that PDS leakages have fallen from $54 \%$ to $42 \%$ by $2011-12,{ }^{21}$ however one has to understand that $42 \%$ is still a substantial number and cannot be expected to resolve through conventional methods. Give Directly, a nongovernmental organization along with IPA (Innovations for Poverty actions), has been promoting cash transfer in several African nations while at the same time fine tuning the flaws as it encounters. Delhi government in 2012 launched the 'Anna Shree Yojana' on similar lines as a pilot project. Similarly, a study done by Self Employed Women's Association (SEWA) organization in Madhya Pradesh has also shown encouraging positive signs.

\section{Conclusion}

There was a very important point made by National Rural Employment Guarantee Act (NREGA) experts in a conference in Delhi $^{22}$ where they said that studies have proved that a very less

${ }^{18}$ Devesh Kapur PM. (Vol. 43, No. 15 (Apr. 12 - 18, 2008). The Case for Direct Cash Transfers to the Poor. Economic and Political Weekly), 37-41, 43.

${ }^{19}$ Masiero PS. ( Vol.50, Issue No. 45, 07 Nov, 2015). Will the JAM Trinity

Dismantle the PDS ? Economic and Political Weekly, 40-43.

${ }^{20}$ Davala S. (2015, July 30). Another Kind of Welfare . Retrieved March 20, 2018, from Indian Express.

${ }^{21}$ Anjali Bhardwaj ND. (2016) PDS in Danger. Economic and Political Weekly

, Vol. 51, Issue No. 38, 17 Sep, 2016

${ }^{22}$ Report. (2008, November 25). National Conference of Legal Experts on percentage of the population receives work for the entire duration of NREGA and thus do not get complete payments. Direct cash transfers will remove this anomaly as the complete money will be deposited in their accounts directly. Also contrary to the criticism, DCT will, instead of the shrinking of the state's role, will help in expanding the state's involvement and reach in issues where earlier it couldn't due to several shortcomings. Several basic things like scholarships to socially backward community students, pension for old age groups, healthcare benefits, which currently have to pass through extensive red tape can be by passed through directly transferring cash to their accounts.

Although one has to agree, that providing cash transfers to such a huge country like India, where just making people literate has proved to be a mammoth task over the last 70 odd years of independence is no mean task. However, as recommended by the Shanta Kumar committee in its PDS reforms initiatives, ${ }^{23}$ cash transfers is the future and should be first initially started in the large cities where the chances of it getting successful is high and we can then expand it accordingly. Also, DCT is an experiment whose time has come, especially after the comprehensive failure of the existing centrally sponsored mechanism to eradicate income inequality through its welfare conception, which has done nothing but, reinforce the status quo if not make matters worse. Critics of the cash transfer model should first justify why the existing failed policies which have been a major hurdle in the development agenda of our country should be continued. Income inequality is not a regional malice but a global epidemic, which we have to tackle now. Unfounded skepticism based on isolated gimmicky research and fear of the unknown can be detrimental in helping India take the next big calculated leap of faith and revolutionize the way social security measures are delivered and relieve us of the stigma of Income Inequality.

\section{Acknowledgments}

None.

\section{Conflict of interest}

Author declared there is no Conflict of interest.

\section{References}

1. Damodaran H. Pay Fertiliser Subsidy Through Swipe Card: Iffco Favours Crediting Amount to Bank Account Through RFID. Hindu Business Line. 2007. 5 p.

2. Mehrotra S. Introducing Conditional Cash Introducing Conditional Cash Transfers in India: A Proposal for Five CCTs. New Delhi: Planning Commission; 2010.

3. Kapur D. The Shift to Cash Transfers: Running Better But on the Wrong Road? Economic and Political Weekly. 2011;46(21):80-85.

4. Narayanan S. A Case for Reframing the Cash Transfer Debate in India. Economic and Political Weekly. 2011;46(21):41-48.

NREGA. Retrieved March 2018, 2018, from PUSA, New Delhi. : http://nrega. nic.in/Minutes_Experts252008.pdf

${ }^{23}$ Kumar S. (2015, January). Report of the High Level Committee on Reorienting the Role and Restructuring of FCI. New Delhi: Government of India. 